\title{
iUBICOM '10: The 5th International Workshop on Ubiquitous and Collaborative Computing
}

In conjunction with the 24th BCS Conference on Human

Computer Interaction ( $\mathrm{HCl} 2010)$

University of Abertay, Dundee

7 September 2010 


\section{Abstract}

Following four successful previous iUBICOM workshops, the theme for the 5th iUBICOM workshop, iUBICOM 10, was 'balancing technological and human factors for better design of ubiquitous computing'.

A particular focus of this workshop was how user needs can be interpreted given new interaction models and unfamiliar technologies. We ask how the challenge of understanding user needs around factors such as speed, transparency, efficiency and quality of service can be met for a range of ubiquitous computing systems of varying interaction styles with different applications. 


\section{Full Synopsis}

Ubiquitous computing throws up a number of design challenges. These systems feature multi-device architectures and complex interactions. They are often part of the environment, where they host a range of everyday activities in ways that imply new kinds of user involvement. With these sorts of systems, it is important to understand the way systems and people work in the environments which are to be augmented. The purpose of this workshop is to bring multi-disciplinary researchers together in order to discuss different models and theories that can be used to design and evaluate ubiquitous computing systems given these issues, in order to balance technological innovation with adequate consideration for the needs of users.

A particular focus of iUBICOM'10 was how user needs can be interpreted given new interaction models and unfamiliar technologies. We ask how the challenge of understanding user needs around factors such as speed, transparency, efficiency and quality of service, can be met for a range of ubiquitous computing systems of varying interaction styles with different applications. Applications can include wayfinding systems, smart homes, assistive technologies, mobile games, and collaborative systems. Interaction styles include, as well as familiar forms, increasingly important approaches such as tangible and haptic interaction, gestural interaction, pro-active and 'disappearing' or 'calm' computing, and ambient computing. In order to design and develop systems which can be successfully deployed, it is necessary to take human factors into account. The question motivating this 5th iUBICOM workshop was how this could be achieved best.

The workshop attracted a range of high quality submissions from researchers working the areas ranging from mixed reality interfaces, through semantic web, to wireless sensor networks.

The workshop includes five papers. Liarokapis and Sylaiou present solutions for both museum exhibitions and mobile guides using multimodal mixed reality interfaces based on open standards. Holroyd, Watten and Newbury present a bespoke solution for a real-time reconfigurable audiovisual routing system for capture and playback within a pervasive multimedia environment. Batra and Bawa discuss a framework for semantic discovery of web services. Iqbal, Odetayo and James present an integrated framework for biometric security. Kumar, Verma and Patel discuss a framework for key management scheme in heterogeneous wireless sensor networks for ubiquitous computing environments.

\section{Workshop Co-chairs}

Dr. Rahat Iqbal

Dr. Neeraj Kumar

Dr. Johan Halloran 


\section{Papers:}

Kashif Iqbal, Michael O. Odetayo and Anne James

An Integrated Framework for Biometrics Security http://dx.doi.org/10.14236/ewic/IUBICOM2010.1

Patrick Holroyd, Phil Watten and Paul Newbury Reconfigurable Multimedia Environment http://dx.doi.org/10.14236/ewic/lUBICOM2010.2

Kamal Kumar, A.K. Verma and R.B. Patel Framework for Key Management Scheme in

Heterogeneous Wireless Sensor Networks http://dx.doi.org/10.14236/ewic/IUBICOM2010.3

Shalini Batra and Seema Bawa A Framework for Semantic Discovery of Web Services

http://dx.doi.org/10.14236/ewic/IUBICOM2010.4

Fotis Liarokapis and Stella Sylaiou Experiencing Personalised Heritage Exhibitions Through

Multimodal Mixed Reality Interfaces http://dx.doi.org/10.14236/ewic/IUBICOM2010.5 